\title{
Teoria e prática
}

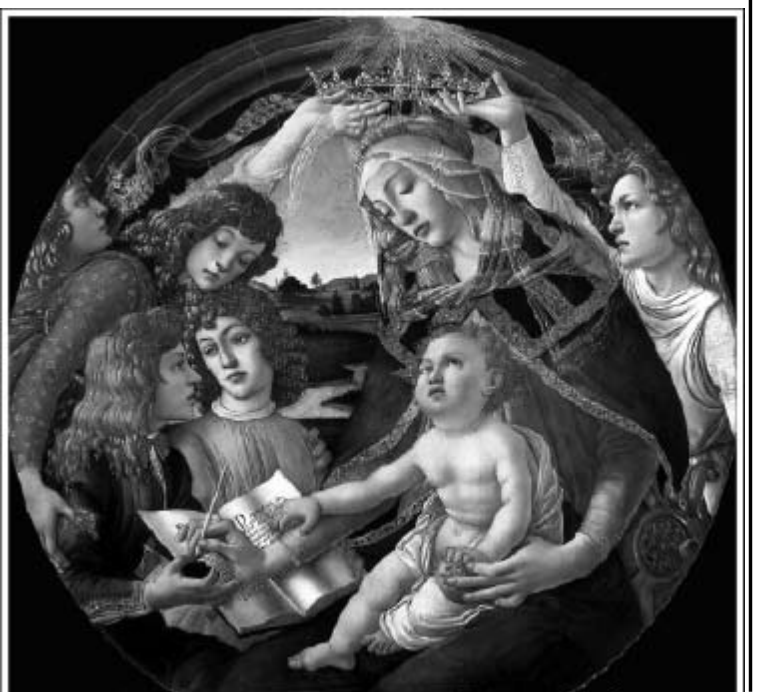





\title{
Paisagem do Casco Histórico de Itajaí, SC: uma análise das potencialidades para o desenvolvimento do turismo cultural
}

Landscape of the Itajaí's historic center: an analysis of the potencialities for the development of the cultural tourism

Paysage du Centre Historique de La Ville de Itajaí: une analyse du potentiel pour le développement du tourism culturel

Paisaje del casco histórico de Itajai: un análisis del potencial para el desarrollo del turismo cultural

\author{
Fernando Luigi Padoin Fontanella* \\ Diva de Mello Rossini** \\ Josildete de Oliveira*** \\ Francisco dos Anjos****
}

Recebido em 31/6/2011 revisado e aprovado em 25/9/2011; aceito em 20/11/2011

Resumo: O objetivo do trabalho foi estudar a paisagem do casco histórico de Itajaí, ocupada a partir do século XVIII, uma cidade do Estado de Santa Catarina - Brasil, e identificar as potencialidades para o desenvolvimento do turismo cultural, a partir das categorias de Cullen (1971), Lynch (1997), Rossi (1995) e de Boullón (2002). A pesquisa bibliográfica, documental e a de campo auxiliaram na identificação dos atributos turístico-culturais.

Palavras-chave: Cidade. Paisagem. Turismo cultural.

Abstract: The objective of the work was to study the landscape of the Itajaí's historic center, city which has been occupied since the XVIII, a city of the state of Santa Catarina - Brazil and to identify the potentialities for the development of the cultural tourism, based on the categories of Cullen (1971), Lynch (1997), Rossi (1995) and Boullón (2002). The bibliographic, documentary and field research assisted in the identification of the cultural tourism's attributes. Key words: City. Landscape. Cultural tourism.

Resumé: L’objectif du travail intitulé Le paysage du centre historique de La ville d'Itajaí, datée du XVIII siécle et située dans l'État de Santa Catarina - Brésil, a éte identifier le potentiel pour le développement du tourism culturel a partir de l'analyse du patrimoine culturel edifié. Cette analyse repouse sur l'approche théorique des auteurs Cullen (1971), Lynch (1997), Rossi (1995) e de Boullón (2002) et sur l'analyse des données découpées de la recherche sur le terrain, qui ont permi identifier les caractéristiques culturelles et le potentiel touristique.

Mots-clés: Ville. Paysage. Tourisme culturel.

Resumen: El objetivo del trabajo fue estudiar la paisaje del casco antiguo de Itajai, ocupado desde el siglo XVIII, una Ciudad del Estado de Samta Catarina y identificar el potencial para el desarrollo del turismo cultural, de las categorías de Cullen (1971), Lynch (1997), Rossi (1995) y Boullon (2002). La investigación de la literatura, documental y de campo ayudó a identificar los atributos del turismo cultural.

Palabras clave: Ciudad. Paisaje. El turismo cultural.

\footnotetext{
* Acadêmico do Curso de Arquitetura e Urbanismo (Univali).

** Graduada em Arquitetura e Urbanismo pela Universidade do Vale do Itajaí, Mestre em Engenharia de Produção (UFSC) e Doutoranda do Curso Administração e Turismo (Univali). Docente e pesquisadora do Curso de Arquitetura e Urbanismo da Universidade do Vale do Itajaí.

*** Graduada em Arquitetura e Urbanismo pela Universidade Federal da Bahia. Mestre em Natureza, Meio Ambiente, Sociedade (DEA - Nature, Environnement, Societé) e Doutora em Geografia pela Université de Caen Basse Normandie, França. Docente e pesquisadora da Universidade do Vale do Itajaí, no Programa de Pós-Graduação Stricto Sensu - Mestrado Acadêmico em Turismo e Hotelaria e no Curso de Arquitetura e Urbanismo.

**** Graduado em Geografia pela Universidade do Vale do Itajaí. Mestre em Geografia - Desenvolvimento Urbano e Regional pela Universidade Federal de Santa Catarina. Doutor em Gestão Ambiental pela Universidade Federal de Santa Catarina. Pós-doutorado em Geografia Urbana pela Universidade do Estado de São Paulo e em Urbanismo e Ordenamento do Território pela Universidade Politécnica da Catalunha. Docente e pesquisador da Universidade do Vale do Itajaí, no Programa de Pós-Graduação Stricto Sensu - Mestrado Acadêmico em Turismo e Hotelaria e nos Cursos de Arquitetura e Urbanismo e Geografia.
} 


\section{Introdução}

Até poucas décadas atrás, grande parcela da população não reconhecia o patrimônio cultural edificado como um dos elementos de perpetuação de nossa identidade cultural, nem tampouco havia movimentos sociais em prol da preservação dos bens patrimoniais monumentais (MORENO, 2002). No Brasil, as ações de proteção e preservação do patrimônio histórico e cultural passaram a ser aplicadas a partir da década de 1930, com a criação do Serviço do Patrimônio Histórico e Artístico Nacional. No entanto a intensificação da aplicação das políticas patrimoniais ocorreu nas décadas de 1980 e 1990, quando a elite cultural bem como os governos estaduais e municipais foram estimulados a preservar os centros das cidades - seus bens culturais, a memória coletiva e a identidade cultural, como elementos essenciais da vida (ENDRES; OLIVEIRA; MENEZES, 2007). Tal contexto permitiu que os centros urbanos fossem revitalizados e entendidos como os lugares mais dinâmicos da vida urbana, animados pelo fluxo de pessoas, veículos e mercadorias, historicamente eleitos para sediar instituições públicas e religiosas. Esse somatório de atividades confere ao centro urbano, até os dias atuais, um significado que extrapola os limites da própria cidade (VARGAS; CASTILHO, 2009).

A criação desse cenário possibilitou que a sociedade atual compreendesse a importância dos bens construídos, valorizando-os, ao entender que eles são os signos que registram o passado.

Esse panorama promoveu o incremento do turismo cultural no Brasil, que, neste milênio, tem sido um grande aliado das políticas públicas de preservação, revitalização e restauro da história edificada, promovendo discussões junto à sociedade $\mathrm{e}$ aos órgãos de fomento à cultura, nas quais o tema central é o patrimônio histórico edificado. E assim, impulsiona o desenvolvimento de estudos do fenômeno turístico associado a outras ciências, como arquitetura e urbanismo, promovendo a compreensão da relação do turismo com a cidade e seu o patrimônio edificado (EMBRATUR, 1991).

Essa mudança de condição, associada ao desenvolvimento tecnológico e à globali- zação, fez com que o território deixasse de ser o locus da produção para se tornar objeto de consumo e palco de diversas atividades. Dessa forma, o processo assumido pelos novos meios de comunicação e marketing instaura uma verdadeira competição entre lugares, transformando a paisagem em um produto para ser cobiçado por investidores, políticos, moradores e turistas (VARGAS; CASTILHO, 2009).

Portanto entender a formação do espaço e da comunidade leva-nos a compreender que o espaço é social, e que a sua transformação ocorre a serviço das necessidades do homem, no decorrer de sua história. Essa mudança que vai sendo armazenada ao longo do tempo, na estrutura física da cidade, resulta na permanência de fragmentos de inúmeras paisagens, vivenciadas pela sociedade local em diversos momentos da história.

Essa paisagem, que foi sendo alterada devido à dinamicidade do processo evolutivo dos fatos urbanos, mantém registros que nem sempre estão apenas nos edifícios, mas na associação deles aos traçados urbanos que são elementos de maior tempo de permanência e que, juntos, configuram o produto da arte do ambiente urbano (CULLEN, 1971; ROSSI, 1995).

Com intuito de estudar e decodificar esses processos registrados nos núcleos urbanos, Rossi (1995) escreve a Teoria da Permanência, baseado nas doutrinas da geografia social de Tricart, da persistência de Marcel Poète e da Iluminista de Milizia. Nessa obra, o autor designa categorias de análise para leitura dos fenômenos urbanos, momento em que a apreciação deve ser restrita a "um pedaço da cidade", a um conjunto de edifícios, cujo princípio arquitetônico é único e imutável. Também, ao desenho urbano dessa parte da cidade, que configura a construção de um ambiente homogêneo, coordenado e contínuo, capaz de interpretar a consistência da paisagem local, na qual buscam a compreensão das leis, motivos e ordens, que estão ligados ao retrato da realidade histórica. (ROSSI, 1995).

Essa instigante temática originou outras obras que também se apropriam de categorias para análise da paisagem urbana. As mais representativas foram publicadas em 1960 por Lynch (1997), em 1961, por Cullen (1971) e, em 1966, por Rossi (1995). A primeira obra 
que buscou a relação com a paisagem turística foi publicada, em 1985, por Boullon (2002), que se refere à análise do espaço turístico urbano empregando principalmente os conceitos de Lynch. Portanto, esta pesquisa utiliza essas categorias de análise para identificar a existência de potencialidades que possibilitem transformar esse sítio em um destino que tira partido da paisagem como matéria-prima para o desenvolvimento do turismo cultural, ou seja, se ela possui potencial para atrair a demanda turística, principal motivação desta pesquisa. Sendo assim, o objeto deste estudo optou pelo Centro histórico de Itajaí, uma cidade catarinense com mais de 100 anos de existência, com um casco histórico preservado, considerando seu traçado urbano, edificações monumentais e populares.

A problemática descrita e os referenciais teóricos supracitados incitam a análise de núcleos históricos, com intuito de identificar suas peculiaridades e potencialidades, como também de desenhar as ações a serem implantadas para que a paisagem aperfeiçoe a experiência do turista, a partir de roteiros que estimulem o olhar, provoquem curiosidade, para que o leve a descobrir muito mais sobre o lugar e seus habitantes, como hábitos e costumes, sua história e lendas.

A criação dessa rede de atos tende a instituir uma comunicação efetiva do visitante com o residente, promovendo a preservação e o desenvolvimento das comunidades locais, agregando valor ao produto turístico proveniente da cultura material.

Dessa forma, o casco histórico de Itajaí se configura como um quadrilátero (Figura 1), foco desta análise, que inicia no marco zero da cidade, ocupado no século XVII, atual Praça Vidal Ramos, e segue até a Rua Tijucas. A necessidade de delimitar o espaço de estudo se baseia na teoria de Rossi (1995), a qual afirma que, para avaliar o lugar, é preciso estabelecer limites que compreendam as escalas da rua, do bairro e da cidade e determine a reconstituição da formação espacial da cidade, a partir de elementos deduzidos da história, da geografia e da arquitetura, consideração que se estende aos edifícios, às ruas e aos monumentos urbanos.

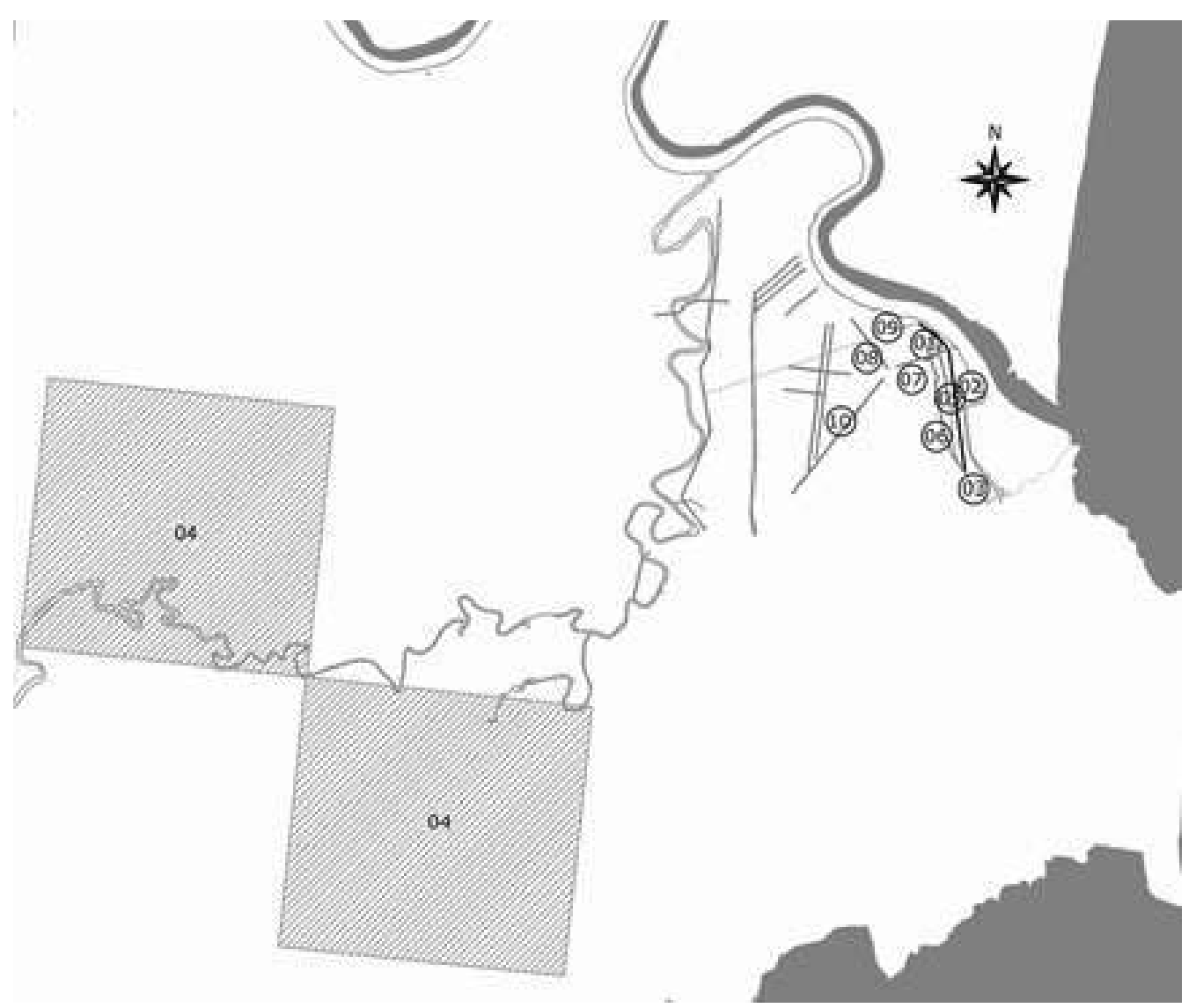

Figura 1 - Quadrilátero que origina o Circuito Turístico Cultural.

Fonte: Acervo do autor, 2011. 
Ao estudar as categorias de análise da paisagem, constata-se que todos os autores que respaldam este estudo avaliam os elementos da cidade de forma similar. No entanto Lynch (1997) categoriza de forma mais abrangente, cria seis macrocategorias vias, marcos, limites, pontos nodais e bairros. Boullón (2002) apropria-se das categorias de Lynch para ler a paisagem artificial do espaço turístico urbano, e os demais passam a pormenorizar os dados a serem observados. Dentre eles, Cullen (1971) é o mais descritivo, pois, apesar de categorizar a análise do espaço em três aspectos - óptica (Visão Serial), local e conteúdo, apropria-se das reações emocionais que o ambiente suscita para ler a paisagem, fato que resulta no desdobramento de uma série de subcategorias, as quais podem ser associadas às descritas por Lynch (1997), o autor mais sintético.

Para delinear as áreas de estudo, definiram-se cinco trajetos que formam um circuito cultural, conforme segue: trajeto 1, inicia-se no Marco Zero em direção ao Mercado Público; trajeto 2, parte do Mercado Público em direção à Rua Lauro Müller e Pedro Ferreira; trajeto 3, inicia-se na Rua Silva e vai até a Rua Tijucas; trajeto 4, começa na Rua Tijucas, junto ao limite do Porto, em direção ao do Largo da Igreja Matriz do Santíssimo Sacramento; e, trajeto 5, que possibilita o fechamento do circuito, parte da Praça da Matriz em direção ao Marco Zero.

Vale ressaltar que este artigo foi estruturado a partir da análise parcial dos dados coletados para uma tese de doutorado e parte da premissa de que a cidade é fruto da síntese edificada da forma de viver de uma sociedade; portanto, produto de criação social, testemunho dos níveis alcançados pela cultura humana, a qual revela fatos que iniciaram e deram continuidade a sua construção.

\section{Da cidade ao turístico Centro Histórico}

A história das cidades mostra que as transformações de ordem econômica e social deixam sinais, pois promovem a adequação da estrutura, da forma e da imagem da cidade. Assim, o século XX foi marcado pela ascensão da urbanização e industrialização, quando grande parte da população mundial passou a viver nos centros urbanos.
Pensar e sentir a cidade, viver a cidade, decifrar a história deste viver, suas mutações e diferenças tornaram-se tema de estudo para muitos pensadores desse período (BARROS, 2007). Dentre eles, dois grandes nomes revolucionaram a arquitetura mundial, Le Corbusier e Gropius, ambos em países que viveram a crise do período marcado pelo fim de uma guerra, mas que se apropriaram da arquitetura para desenhar uma nova realidade e instituir o conceito de funcionalidade, produto que representa essa nova sociedade democrática, emoldurada pela pureza das formas e perfeição das estruturas (ARGAN, 2001).

Já no final do século $X X$, ressurge uma tendência para a adoção do modelo da cidade aberta da Antiguidade, movimento esse proveniente dos crescentes desencontros entre a cidade e a arquitetura, renegando as obras que nascem desvinculadas do corpo social, produtos de um clã que se preocupa exclusivamente com a aprovação de arquitetos famosos. Algumas escolas de arquitetura, como a de Sevilha, de Veneza e de Lisboa, opuseram-se a esse movimento, revisando as teorias de projeto que sucederam a crise do movimento moderno atual. Estas deram início aos seus trabalhos com a seleção de alguns arquitetos, como Aldo Rossi e Rem Koolhaas, que marcaram o momento inicial e final da pós-modernidade, discutindo os problemas da arquitetura do nosso tempo e a compreensão dos fenômenos urbanos (ARGAN, 2001; POZO y BARAJAS, 2009).

No entanto, no período após a Segunda Guerra Mundial (1939-1945), foi que surgiram as discussões sobre as dinâmicas da vida urbana e atividades nos centros urbanos. Os "centros históricos" passaram a ser tema de discurso dos políticos, técnicos e jornalistas, bem como da população em geral, tornandose matéria de importância frente à transformação das cidades. (MORENO, 2002; POZO y BARAJAS, 2009).

Cabe destacar que houve três importantes períodos nos processos de intervenção dos centros urbanos, descritos pelas autoras Vargas e Castilho (2009). O primeiro, caracterizado pela Renovação Urbana (1950 a 1960), marcado pelo Movimento Moderno (Carta de Atenas, 1933) e a recuperação urbana (CIAM). O tema central do CIAM de 
1951 foi o ideal dos centros urbanos - coração da cidade. O propósito daquela geração era demolir e construir para renovar, processo esse cujo modelo foram os Estados Unidos da América. Nesse período, na Europa, ocorria a implantação dos projetos urbanos com ênfase nos espaços para uso exclusivo de pedestres, nas principais ruas do comércio. Já o segundo período, Preservação urbana (1970 e 1980), nega o Modernismo e implanta o Estilo Internacional, quando as propostas de intervenção aproximam-se das versões europeias, com a restauração dos velhos centros urbanos. Esse período foi caracterizado pelo surgimento de grande número de normativas e leis visando salvaguardar os "centros históricos". O último período, de Reinvenção urbana (1990) e que vigora até os dias atuais, é quando a cidade passa a ser pensada como um empreendimento a ser gerenciado, mediante o uso do planejamento. Surge então, no Brasil, o Programa Monumenta (1999), que visa ao resgate, à conservação e à revitalização do patrimônio histórico e cultural urbano e prevê a criação do Fundo Municipal de Preservação que, atualmente, mantém o Programa de Aceleração do Desenvolvimento das Cidades Históricas.

Este é o momento em que o centro histórico da cidade passa a ser reconhecido como um importante objeto, detentor de uma diversidade de formas e funções, pretéritas e presentes, de signos e significados que ganharam ou perderam a importância social no decorrer do tempo, que deflagra a formação de uma memória patrimonial que deverá responder às necessidades das sociedades do futuro (MORENO, 2002; PEIXOTO, 2004).

Apesar dessa movimentação em prol da preservação, a globalização fez com que muitas cidades industriais perdessem a sua identidade, considerada um trunfo essencial para o desenvolvimento da economia cultural, pois a individualização promovida pela cultura local acentua sua identidade e marca seu lugar no panorama mundial (VAZ, 2004).

Dentro desse contexto, torna-se importante destacar que o turismo cultural teve sua origem no final do século XVIII e início do século XIX, a partir do desenvolvimento dos meios de transporte, propiciado pela revolução industrial e motivado pelo surgimento da classe burguesa, que buscou elitizar-se não só pelo dinheiro, mas também pelo conhecimento (BARRETTO, 1995).

Entretanto o Brasil entra como polo receptor de turistas estrangeiros, somente após a segunda Guerra Mundial, impulsionado pelo seu patrimônio, formado por belezas naturais ímpares e um rico patrimônio histórico (AZEVEDO, 2002; GOULART; SANTOS, 1998).

O despertar do turismo cultural para o sul do Brasil é ainda mais recente e tem seu início em torno de 1980, quando a conscientização dos valores, da diversidade étnica que povoou e colonizou o sul do Brasil foi o ponto de partida para a exploração desse filão. Os Estados do Paraná, Santa Catarina e Rio Grande do Sul deram início ao turismo cultural nos anos de 1990, com os programas governamentais que incentivaram as prefeituras dos municípios com concentrações étnicas de origem italiana ou alemã, a explorar o seu potencial cultural promovendo festas típicas de suas tradições, atraindo significativo número de visitantes (SANTOS; GOULART, 1998).

Atualmente, o turismo cultural está impondo formas atípicas de convivência, envolvendo recursos tecnológicos avançados, shows espetaculares, mas também exigindo autenticidade das manifestações. Esse tipo de turismo implica a busca por diferenças, traçadas pela cultura, pelo patrimônio e pela natureza. Ele representa um dos veículos mais importantes de divulgação cultural e ambiental, que emerge dele próprio, como um instrumento de reafirmação da cultura e de patrimônios singulares (AZEVEDO, 2002).

Sendo assim, o segmento turístico ganha importância mundial devido ao grande impacto que causa no cotidiano das sociedades, impulsionado pela busca de sustentabilidade e de participação da comunidade local. Ele se apresenta como um elemento desafiador, que impulsiona o desenvolvimento de análise da paisagem de centros históricos com intuito de identificar potencialidades que possam vir a subsidiar, a partir do patrimônio histórico construído, o desenvolvimento de estratégias para o incremento do turismo cultural na localidade.

Assim, o diagnóstico desenvolvido detém-se apenas ao patrimônio construído da cidade de Itajaí como um dos instrumentos que poderão nortear o planejamento do 
turismo cultural para esta localidade, pois, desde a sua origem, o turismo incorpora o patrimônio cultural como um dos principais componentes dos roteiros e programações.

\section{Evolução histórico-urbana de Itajaí}

Nos séculos XV e XVI, as terras portuguesas eram demarcadas pelo Tratado de Tordesilhas. Nesse período, o Brasil colonial era constituído pelas capitanias hereditárias, e as terras catarinenses pertenciam à Capitania de Sant'Ana, doada a Pero Lopes de Souza, sendo que os primeiros núcleos fundados foram São Francisco do Sul (1658), Desterro (1672) e Laguna (1684). A fundação da cidade de Itajaí ocorreu em 1650, pelos vicentistas, devido à necessidade de reconhecimento do extenso litoral brasileiro (FUNDAÇÃO CULTURAL DE ITAJAÍ, 2009; FUNDAÇÃO GENÉSIO DE MIRANDA LINS, 2009).

O Rio Itajaí foi um atrativo para os portugueses e sua história iniciou-se em 1658, com chegada do paulista João Dias D' Arzão, fundador de São Francisco do Sul. Mas, a partir de 1823, foi que o povoado passou a ser organizado por Agostinho Alves Ramos, sendo que, em 1824, fundou o Curato do Santíssimo Sacramento do Itajaí (FUNDAÇÃO CULTURAL DE ITAJAÍ, 2009).

Em 12 de agosto de 1833, o povoado de Itajaí foi elevado à Paróquia - Paróquia do Santíssimo Sacramento, mas, somente em 1859, iniciaram-se as mudanças políticoadministrativas, quando foi elevada à categoria de Vila. Em 1860, o município de Itajaí foi oficialmente fundado, acelerando o desenvolvimento das atividades portuárias uma vez que não estaria mais subordinada à Câmara Municipal de Porto Belo. Em 1868, foi criada a comarca de Itajaí, elevada, em 1876, à categoria de cidade (FUNDAÇÃO CULTURAL DE ITAJAÍ, 2009).
No decorrer de sua história, a cidade sofrera várias enchentes, mas, a de 1880 foi que acarretou o maior prejuízo, pois interrompeu o fluxo das mercadorias para o Porto, por meio da Rua Pedro Ferreira, principal via de transbordo das atividades portuárias da época. Esse fato gerou a construção de um novo acesso para a Barra do rio, a Rua Tijucas, que passou a fazer a conexão de entrada dos produtos oriundos do Alto Vale do Itajaí até a Barra do Rio (FUNDAÇÃO CULTURAL DE ITAJAÍ, 2009; FUNDAÇÃO GENÉSIO DE MIRANDA LINS, 2009).

\section{Análise do potencial turístico da paisa- gem do Centro Histórico de Itajaí}

A história da cidade continua até os dias atuais, mas para esta pesquisa, o marco que delimita a área urbana é a construção da Rua Tijucas, recorte realizado a partir dos preceitos da Teoria da Permanência de Aldo Rossi (1995), que determina a reconstituição da formação espacial da cidade, a partir dos fatos urbanos e define que, para avaliar o lugar, é preciso estabelecer limites que compreendam as escalas da rua, do bairro e da cidade. Portanto a apropriação dessa via, construída no passado, como um indicador das condições dos organismos urbanos da cidade atual, na qual há registros de fatos históricos, subsidia a comparação entre o passado e o futuro.

Para ler a paisagem, dividiu-se o circuito em cinco trajetos que foram percorridos a pé (Figura 2), nos quais foram identificados os atributos, as motivações e os bens a serem consumidos pelo turismo. Essa investigação parte da escala da rua e configura o traçado urbano da cidade do século XIX, momento em que se associaram os dados coletados à Teoria da Permanência de Rossi (1995) aos conceitos de Visão Serial de Cullen (1971). 


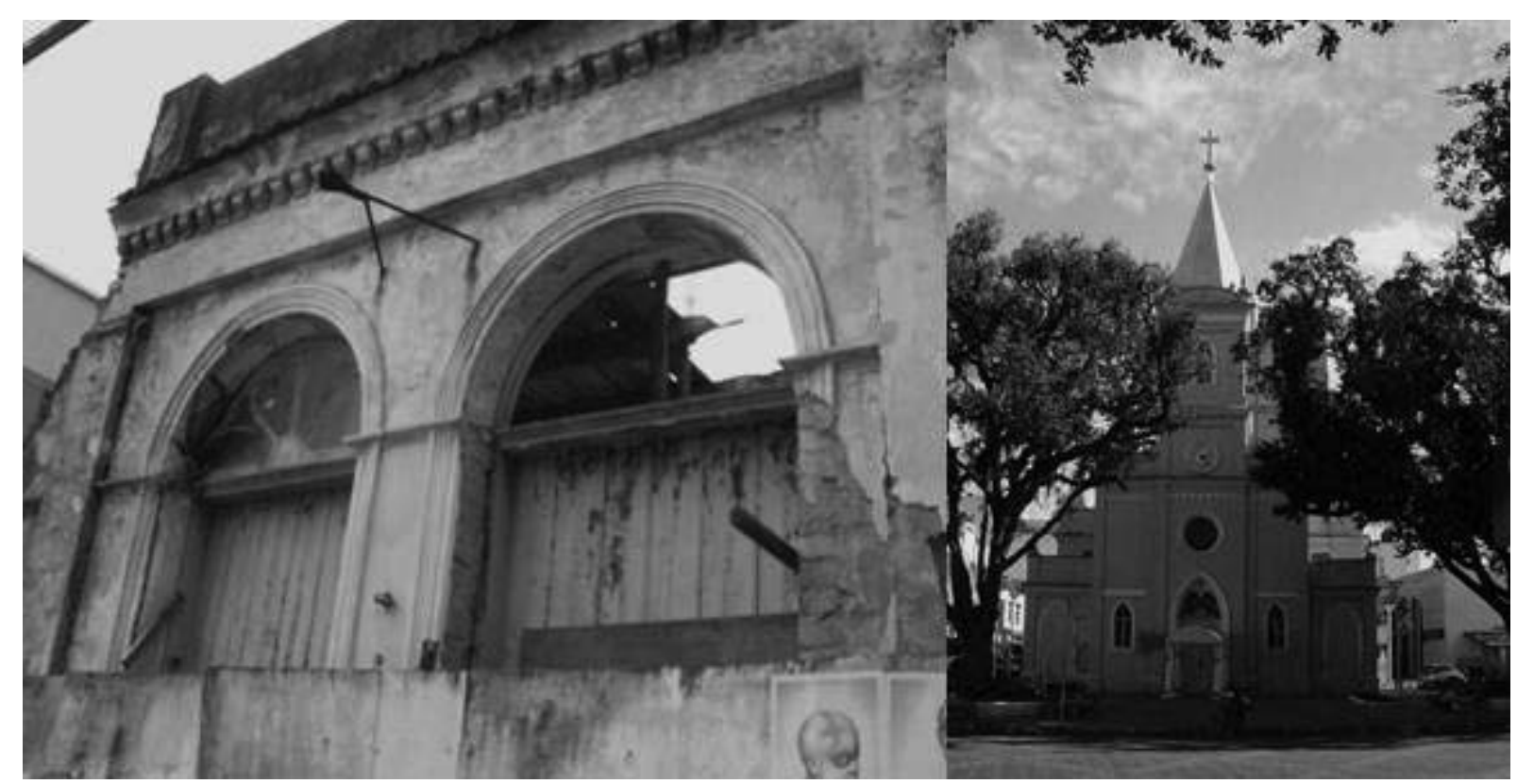

Figura 2 - Cinco trajetos que formam Circuito para ser percorridos a pé.

Fonte: Acervo do autor, 2011.

A caminhada iniciou-se na Praça Vidal Ramos em direção ao Mercado Público - trajeto 1 . As percepções do transeunte iniciam-se na praça, identificando o campanário da Igreja Imaculada da Conceição (1824) como ponto focal, pela sua altura. E o monumento do Marco Zero, pela posição privilegiada em meio ao vazio urbano. A Igreja do Santíssimo Sacramento (atual Igreja Imaculada da Conceição) e o cemitério sofreram uma série de intervenções ao longo do tempo, tombados pelo
Estado desde 1998. Sobre o arco do cruzeiro, existe um mural em alto relevo com sete anjos, de autoria de Dide Brandão. Sobre o altar, está a imagem de Santo Agostinho Alves Ramos, de origem portuguesa, talhada em madeira, ostenta uma coroa em prata lavrada (FUNDAÇÃO CULTURAL DE ITAJAI, 2009). Ao se voltar para o Rio Itajaí, surge pela primeira vez uma perspectiva grandiosa, ladeada pelo edifício ícone do Píer Turístico, como mostra a figura 3.

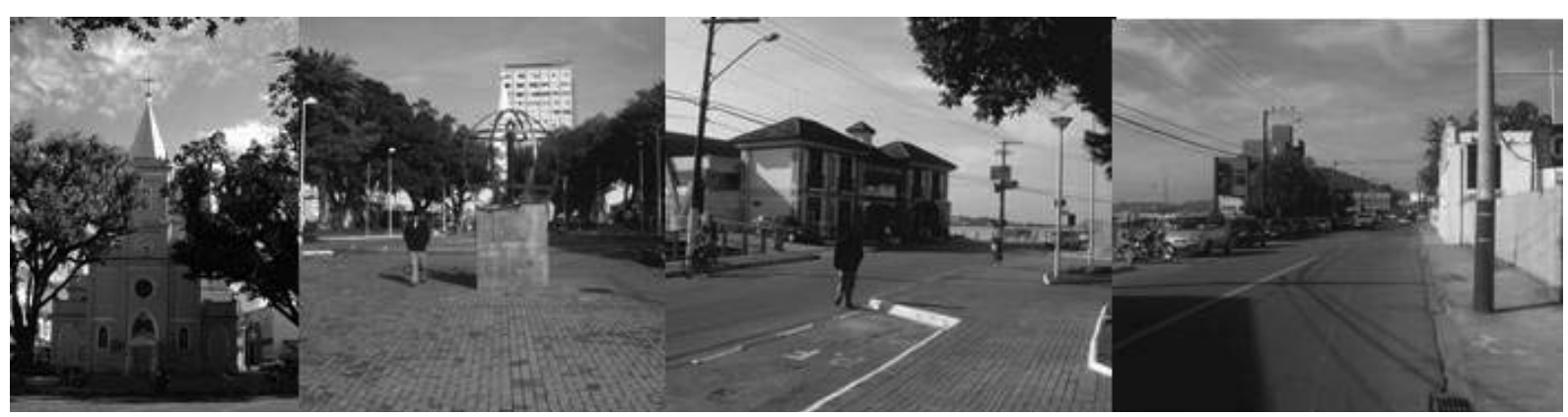

Figura 3 - Igreja Imaculada Conceição, Marco Zero, Edifício do Pier turístico e perspectiva da caminhada de saída da Praça Vidal Ramos em direção ao Mercado Público.

Fonte: Acervo do autor, 2011. 
Logo, as cores da paisagem se apagam, os edifícios são brancos e cinza, e há pouca vegetação. Em seguida, a ampla visão do rio é interrompida por algumas edificações. O Mercado Público se revela por trás dos edifí- cios e imputa cores marcantes na paisagem, surgem "ruídos" no cenário, promovidos pela comunicação visual e fiação elétrica aérea, indicando uma maior apropriação do espaço (Figura 4).

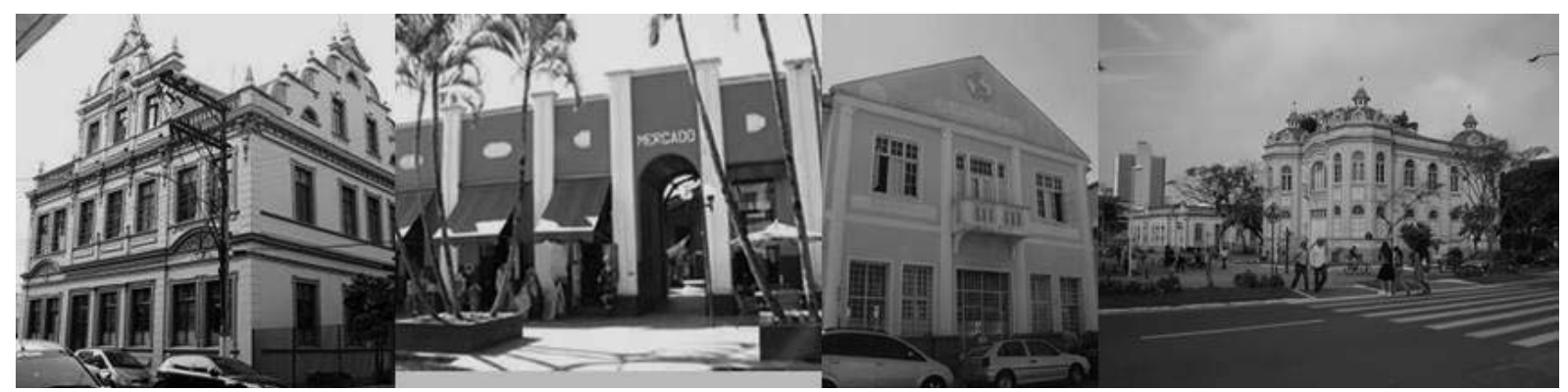

Figura 4 - Perspectiva da caminhada de saída da Praça Vidal Ramos em direção ao Mercado Público, Mercado Público (vista externa e interna).

Fonte: Acervo do autor, 2011.

Ao entrar no Mercado Público, de 1917, a sensação é de revelação: interior rico em elementos de ordem cultural. As aberturas propiciam a vista do exterior para o interior desse edifício que começou a ser projetado em 1916, com arquitetura eclética de origem germânica, que se destinou à venda a varejo de gêneros secos e molhados. Em 1936, após um incêndio, foi modificado externamente, os frontões foram demolidos e a arquitetura adaptada ao movimento Art Deco. Tombado pelo Estado em 2001, atualmente é um espaço que conserva as tradições populares, principalmente de origem açoriana (FITUR, 2009).

Ao olhar o trajeto no sentido contrário, surge outro ícone, o edifício dos Práticos do Porto, de arquitetura contemporânea e que volta as costas para o rio, reduzindo a magnitude de sua perspectiva, pois caracteriza-se como um local utilizado para observação da paisagem. Na continuidade, a vegetação torna-se um elemento singular e reforça a relação entre o aqui e o ali: a cidade de Navegantes que fica na outra margem do rio. Ao concluir esse trajeto, surge o Píer Turístico como outro elemento singular junto à Praça Vidal Ramos (1938), na qual a vegetação secular se sobrepõe ao campanário.
O trajeto 2 parte do Mercado Público em direção às ruas Lauro Muller e Pedro Ferreira. As percepções da Rua Lauro Muller são singulares em relação às outras, aqui o trajeto é praticamente composto de espaços abertos. A sinuosidade da via fecha o visual e confere destaque ao edifício do atual Hotel Rota, edificação de valor histórico e antigo Hotel Brasil, de 1897. Sua arquitetura é em estilo República, de inspiração romântica e neoclássica vigente no final do século XIX, e característico da burguesia urbana brasileira. Considerado um local de realização de grandes negócios e ponto das informações provenientes do Continente Europeu, durante a primeira e a segunda Guerra Mundial. Na sequência, surge a Casa Konder (1904), com arquitetura de traços germânicos, em estilo haneático, é a atual sede da Livraria Casa Aberta. Em seguida, está o edifício da atual Fundação Cultural - Casa Bughardt (1902), em estilo eclético também de influência germânica (GALLATO, 2008).

Na sequência, o gabarito da via promove o fechamento do visual, e aparece uma perspectiva delimitada. Identifica-se uma série de edificações históricas, primeiro individualmente, depois em conjunto (Figura 5). 


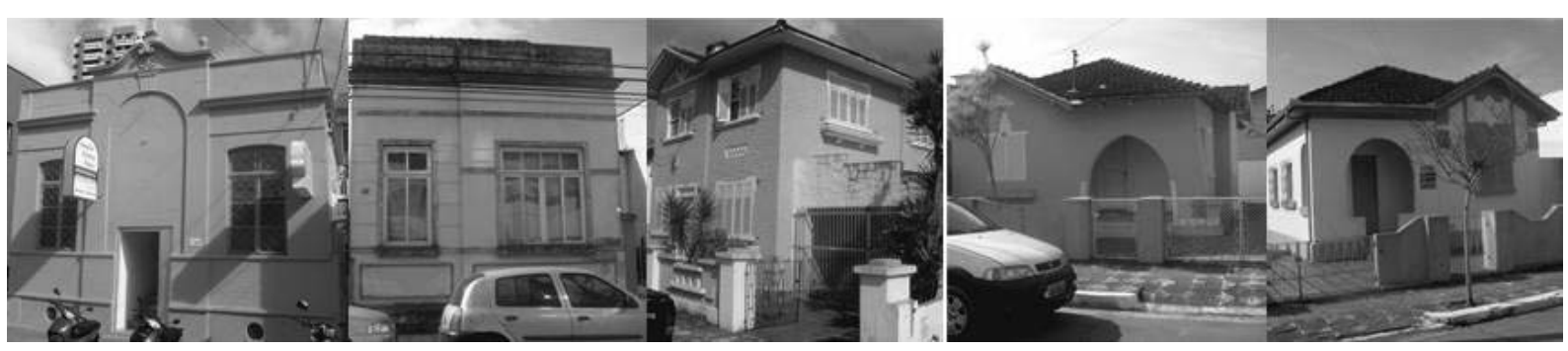

Figura 5 - Perspectiva da caminhada da rua Lauro Muller para a Praça Vidal Ramos, sequência das edificações ao se afastar da Praça.

Fonte: Acervo do autor, 2011.

O fato que mais chama atenção nesse trajeto é a ordem cronológica das edificações, quanto mais próximo da Praça Vidal Ramos, mais antigas são as edificações e, quanto mais distantes, mais recentes - década de 1960.

Continuando o percurso em direção à Rua Pedro Ferreira (antiga Rua do Comércio), surge uma via não reticular, na qual a sensação é de que se perde a noção do todo e se passa a observar as partes. A primeira é a Casa Malburg (1915), de caráter monumental, foi uma das mais belas casas de Itajaí em estilo eclético, caracterizado pela profusão de ornamentos, principalmente, nas cimalhas e frontões; atualmente abriga os escritórios da Receita Federal. Depois a visão se desdobra, e surge um espaço contínuo e longo até surgir o edifício Genésio Miranda Lins, "redondo", predominando na paisagem devido a sua verticalidade, um ponto focal. Na sequência, surgem edifícios de dois pavimentos que demarcam uma forte horizontalidade. Logo à direita, está a Casa Voigt (1924), que foi sede da firma Almeida \& Voigt e do Banco Inco; em estilo neoclássico, é um exemplar da arquitetura comercial das primeiras décadas do século $X X$, quando a navegação de cabotagem se desenvolveu e inúmeras empresas firmaram-se na cidade. A construção tem duas fachadas, uma voltada para a Rua Pedro Ferreira, e outra, para o Rio Itajaí-Açu (FUNDAÇÃO CULTURAL DE ITAJAÎ, 2009).

Esse cenário possui três camadas, a primeira com as edificações horizontais, a segunda com o elemento vertical e a terceira, ao fundo, com uma imagem composta por novos referenciais - gruas e containers do porto (Figura 6).

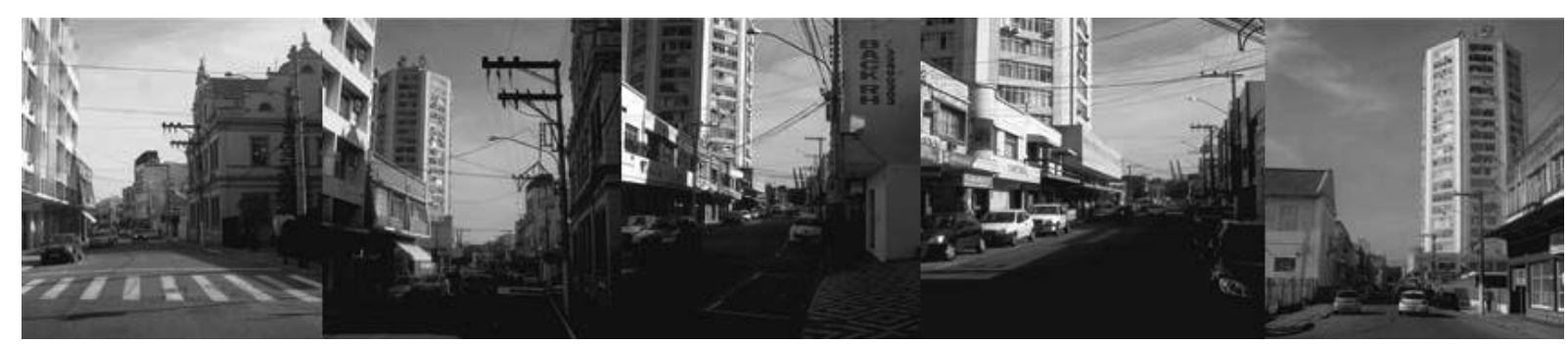

Figura 6 - Perspectiva da caminhada pela Rua Pedro Ferreira em direção ao Porto de Itajaí. Fonte: Acervo do autor, 2011.

Ao chegar próximo ao final da rua, nota-se o Porto com as gruas e containers, que fecham o cenário. Os elementos verticais perdem a magnitude da altura e confundem-se na paisagem, quando surge uma sequência de edifícios de arquitetura típica do início do século XX.
No sentido inverso à caminhada, no primeiro momento o referencial vertical é o edifício redondo, seguido pela Casa Malburg e, por último, pela vegetação que cobre a Igreja Imaculada Conceição.

O fechamento da Rua Pedro Ferreira dá início à Rua Silva - trajeto 3, cujo referen- 
cial é a antiga sede do Porto de Itajaí (1938), em estilo eclético, atualmente em processo de restauração. Logo à direita, surge uma abertura, na qual se pode ver o Rio, aspecto relevante dessa paisagem, já que adiante o trajeto é marcado pela visão do extenso muro, das gruas e containers do Porto, elementos que impedem a visão do Rio Itajaí- Açu e da dinâmica portuária. Já à esquerda, há alguns edifícios cuja arquitetura é típica do início do século XX, construções que abrigavam o comércio e o serviço de apoio às atividades portuárias até o início do ano 2000.

O contraste entre os dois lados da via é evidente, de um lado predomina a monotonia de formas e cores, junto ao Porto, e do outro, uma sequência de edificações de variadas formas, cores, estilos e épocas se intercalam, na qual se destaca o edifício do Colégio São José, conforme demonstra a figura 7.

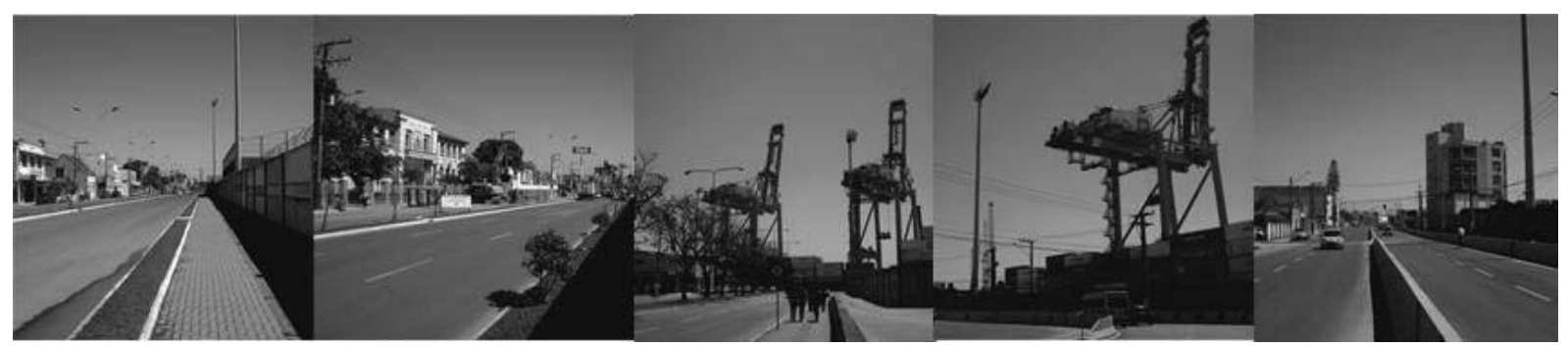

Figura 7 - Perspectiva da caminhada da Rua Silva em direção à Rua Tijucas.

Fonte: Acervo do autor, 2011.

O trajeto 4 mostra a apropriação do espaço pelo grande número de pessoas transitando. Outro elemento que se destaca são as diversas placas publicitárias que confundem as percepções do trajeto. A poluição visual das placas e os cabos de energia elétrica se sobrepõem à arquitetura, escondendo-a e contribuindo para a sua degradação. $\mathrm{O}$ trajeto é praticamente todo fechado, abrese em determinados pontos nos quais há terreno vazio. O comércio de maior porte está recuado ou junto ao cruzamento de vias. Mas o diferencial desse percurso está na identidade promovida pelas gruas do Porto. Como fechamento da via, surge uma massa de vegetação, representada por uma praça com grandes árvores. Ao fundo, a paisagem revela um ponto focal, a Matriz do Santíssimo Sacramento, elemento central e dominante, que, associado às demais edificações, constitui o cenário de uma perspectiva delimitada (Figura 8).

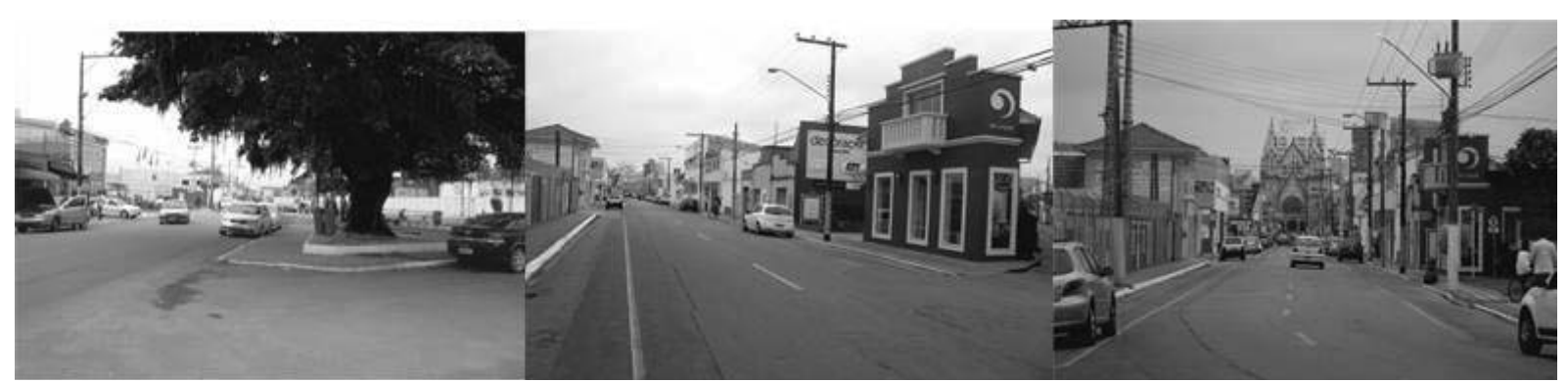

Figura 8 - Perspectiva da caminhada do início da Rua Tijucas até o Largo da Matriz do Santíssimo Sacramento.

Fonte: Acervo do autor, 2011. 
O cruzamento entre as ruas Silva e Tijucas forma um caminho ladeado por edifícios não tombados, em lotes cuja apropriação remete à ocupação colonial, em fila. Com conjuntos habitacionais, de uso misto, ou seja, apresentando comércio no térreo, habitação no pavimento superior e jardins na face posterior do lote, esses edifícios apresentam geometrização na composição das fachadas e coberturas, com detalhes arquitetônicos e urbanísticos que datam do início do século $X X$, momento de intensa transformação econômica do país, conforme demonstra a figura 9.

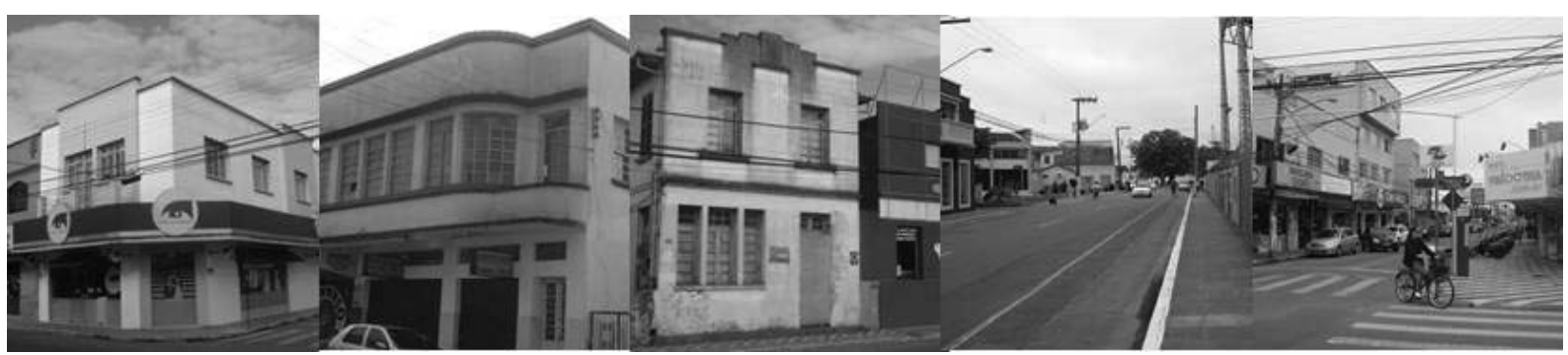

Figura 9 - Perspectiva da caminhada da início da Rua Tijucas até o Largo da Matriz do Santíssimo Sacramento, junto ao conjunto arquitetônico do início do século XX.

Fonte: Acervo do autor, 2011.

No final dessa via, a perspectiva se abre e culmina com a monumentalidade da Igreja Matriz do Santíssimo Sacramento. Nesse cenário, alguns elementos verticais se sobressaem soltos na paisagem: no primeiro plano, a praça e depois a Igreja como ponto focal - considerada um monumento artístico e cultural da cidade de Itajaí. O lançamento de sua pedra fundamental ocorreu em 1940 pelo vigário Pe. José Locks, sendo o edifício projetado pelo arquiteto alemão Simão Gramlich, construtor de inúmeras igrejas catarinenses. Sua arquitetura é composta por elementos românticos, com pinturas, em seu interior, dos artistas italianos Emílio Cessa e Aldo Locatelli. Apresenta em seus vitrais desenhos sobre motivos eucarísticos e bíblicos. No teto, há um imenso painel da Imaculada Concepção da Virgem Maria e, junto ao dossel, uma imponente estátua de Moisés, que desce do Sinai, obra do escultor Teichmann. A Igreja foi inaugurada em 15 de novembro de 1955 (FITUR, 2009; FUNDAÇÃO CULTURAL DE ITAJAÍ, 2009).

O final do trajeto culmina com o cenário da Igreja Matriz e com o Morro da Cruz, à direita da imagem (Figura 10).

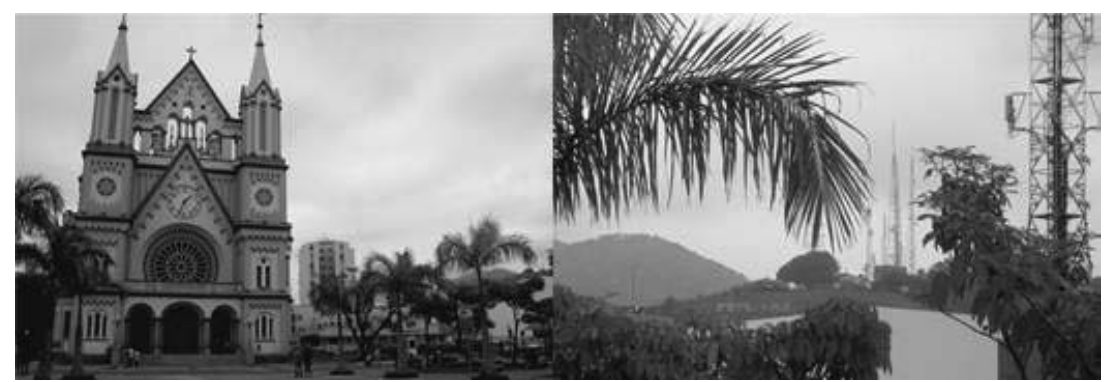

Figura 10 - Final da perspectiva da Rua Tijucas, chegando ao Largo da Matriz do Santíssimo Sacramento, tendo como figura de fundo o Morro da Cruz.

Fonte: Acervo do autor, 2011. 
Saindo da Praça da Igreja Matriz em direção à Rua Hercílio Luz, última parte do trajeto 5, a paisagem promove um desdobramento em duas etapas, sendo que a primeira "abre-se" e, na lateral direta, estão dois edifícios ícones. Um deles, o Palácio Marcos Konder (1925), com estilo eclético e ornamentos clássicos nas pilastras, cimalhas e nas aberturas, em arco pleno, apresenta no hall uma grande janela, que possui características Art Nouveau. É um dos mais importantes edifícios da arquitetura oficial de Santa Catarina, um marco da história da arquitetura e do urbanismo da cidade de Itajaí. Abrigou a Prefeitura Municipal até 1972, tornando-se Museu a partir de 5 de janeiro de 1982. O outro edifício é a Casa da Cultura Dide Brandão (1835), sede da primeira escola do município - Grupo Escolar Victor Meirelles, de tipologia arquitetônica das escolas paulistas do início do século XIX (FITUR, 2009; FUNDAÇÃO CULTURAL DE ITAJAI, 2009).

Nesse trajeto, surgem alguns vazios, como o jardim frontal do Clube Guarani e também a abertura promovida pelo cruzamento de vias. É notável que, nesse cenário, haja edificações de caráter histórico, que se perdem na paisagem. Durante a caminhada, a imersão em um espaço fechado é gradativa, o gabarito das edificações que no início é baixo vai sendo substituído pela verticalidade, que culmina junto ao campanário da Igreja Imaculada Conceição, ponto focal. A apoteose ocorre com o surgimento do Rio Itajaí-açu, que mostra a amplitude da perspectiva e promove a dispersão das pessoas no espaço.

Em síntese, durante todo o trajeto, foram identificados importantes elementos que registram a formação da cidade, traços do contexto urbano, em particular das edificações, exemplares que contam a longa história da sociedade dos séculos XIX e XX e a integram ao cotidiano da cidade do século XXI. Identificam-se, nessa dinâmica urbana, traços da fundação da cidade e da transmissão das ideias da realidade local, perpetuada por meio do conjunto urbano - traçado, usos e monumentos históricos, promovendo o entendimento dos valores e funções que desempenhavam no passado, pois permanecem junto à sociedade e permitem uma conexão da matéria com o dado empírico, os valores espirituais, conforme figura 11.

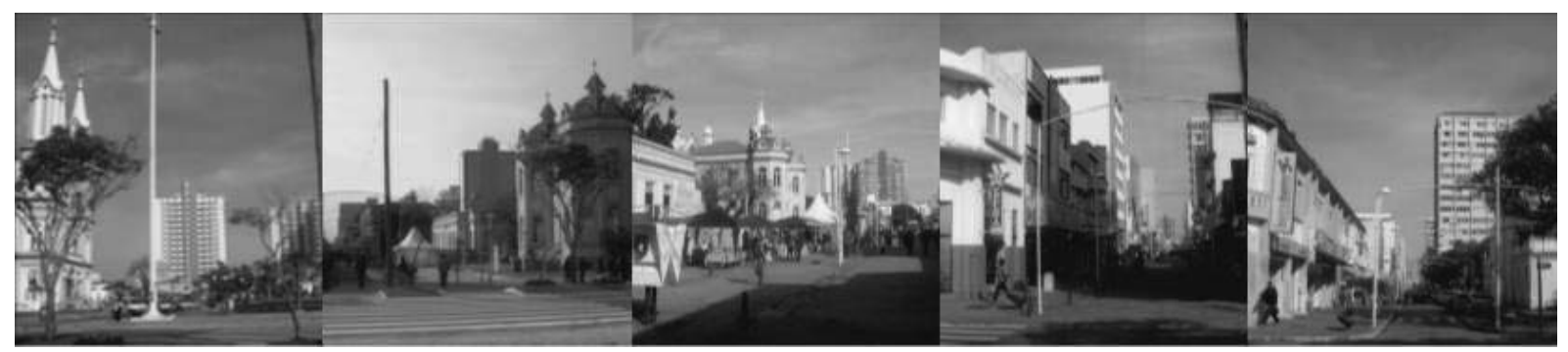

Figura 11 - Perspectiva que mostra o início da Rua Hercílio Luz e o encontro desta via com o Largo da Praça Vidal Ramos.

Fonte: Acervo do autor, 2011.

Ao identificar os registros dessa história, que estão presentes em todos os fatos urbanos que emergem desse espaço habitado, constata-se que essa "cidade é depositária de sua própria história e a busca por estes valores nas profundezas da dinâmica urbana aponta as potencialidades que ela possui para o desenvolvimento do turismo cultural" (ROSSI, 1995). 


\section{Considerações finais}

Constata-se que atualmente a sociedade compreende a importância de se apropriar da cidade como uma oportunidade para vivenciar e reconstruir a memória do passado. Esse fato impulsionou o desenvolvimento do turismo cultural no Brasil. Mas é uma realidade ainda pouco consolidada, uma vez que as iniciativas governamentais de estímulo e proteção aos sítios históricos são recentes, pois datam do início do século XX. Além disso, muitas vezes, têm sido insuficientes para enfrentar a pressão exercida pelos grandes empreendedores imobiliários, fato que, devido ao alto valor da terra, resulta no repentino desaparecimento de sítios históricos, principalmente, daqueles que estão junto aos centros urbanos.

Ao sucumbirem os sítios históricos, não desaparecem apenas a identidade e a memória cultural da sociedade daquele local. Problemas oriundos do século XX se sobressaem, como a estandardização das cidades, processo decorrente da globalização, que, ao difundir uma cultural universal, promoveu a perda dos diferenciais peculiares de cada coletividade.

Portanto as cidades que ainda preservaram essas individualidades poderão despontar no panorama nacional, pois o segmento do turismo cultural busca esses diferenciais, ou seja, atrativos que poderão contribuir com a construção de novos equipamentos culturais.

Sendo assim, a solução para a manutenção da identidade das cidades está na preservação de sua história, dos fragmentos da estrutura física, da permanência de parte das paisagens, outrora vividas pela sociedade local em diversos momentos ao longo de sua trajetória.

Paisagem que foi sendo alterada pelos fatos urbanos que se sucederam, atualmente configura o ambiente urbano, como uma obra de arte. Em síntese, o lugar, a imagem e a identidade são peças fundamentais para a operacionalização da divulgação e promoção da cultura local, cenário que instiga a preservação dos bens construídos, valorizando-os, e promovendo o entendimento de que esses signos que registram o passado conectam ao turismo a cultura imaterial e a cidade.
É com base nesse cenário que o desafio deste trabalho foi associar conceitos e categorias de análise da paisagem de quatro autores diferentes, para identificar potencialidades turísticas na paisagem do centro histórico de Itajaí. Tais conceitos partem do princípio de que a preservação do patrimônio urbano é também uma das principais estratégias para a revitalização das cidades, as quais norteiam o diagnóstico das peculiariades locais e promovem a criação de soluções que evitam a padronização dos espaços e promovem a valorização da "singularidade" da identidade, da cultura local.

Após analisar os conceitos que norteiam o desenvolvimento do turismo cultural e identificar as potencialidades do patrimônio edificado da cidade de Itajaí, constatou-se que a cidade possui a sua singularidade, o seu "tesouro arquitetônico e urbanístico".

No entanto constato que a comunidade e seus dirigentes precisam compreender que o espaço é social e que a sua transformação ocorre a serviço das necessidades do homem, ao longo de sua história. Essa "singularidade material" é um diferencial que associa, além das sofisticações do passado, edifícios e tradições que resistiram ao tempo e podem assumir novas funções no futuro, contribuindo para a valorização desse patrimônio e para o desenvolvimento do turismo cultural, sem deixar de lado as características do espaço e as necessidades da população residente.

\section{Referências}

ARGAN, G. C. Projeto e destino. São Paulo: Ática, 2001. AZEVEDO, J. Turismo o desafio da sustentabilidade. São Paulo: Futura, 2002.

BARRETTO, M. Manual de iniciação ao estudo do turismo. São Paulo: Papirus, 1995.

BARROS, J. A. Cidade e história. Petrópolis: Vozes, 2007. BOULLÓN, R. C. Planejamento turístico. Bauru: EDUSC, 2002.

CULLEN, G. Paisagem urbana. Portugal: Edições 70, 1971.

ENDRES, A. V.; OLIVEIRA, C. M. S.; MENEZES, D. A. Turismo no Centro Histórico de João Pessoa: revitalização, planejamento e não-lugar. Revista eletrônica de Turismo Cultural, p. 1- 20, 2. sem. 2007. Disponível em: $<$ http://www.eca.usp.br/turismocultural.>. Acesso em: 6 set. 2011.

FUNDAÇÃO CATARINENSE DE CULTURA. Lista de bens tombados pelo governo do Estado de Santa Catarina. Disponível em: <http:/ / www.fcc.sc.gov.br/bens/bens. htm>. Acesso em: 19 jun. 2009. 
FUNDAÇÃO GENÉSIO DE MIRANDA LINS. Histórico dos bens tombados do município de Itajaí. Itajaí, SC: Fundação Genésio Miranda Lins/Fundação cultural de Itajaí, 2009.

FUNDAÇÃO ITAJAIENSE DE TURISMO. Atrativos turísticos. Disponível em: <http:/ /www.fitur.itajai. sc.gov.br/2009 >. Acesso em: 20 maio 2009.

GALLATO, B. Mural histórico de Itajaí. Disponível em: <http://muralhistoricodeitajai.blogspot.com>. Acesso em: 12 maio 2010.

INSTITUTO BRASILEIRO DE TURISMO - EMBRATUR. Legislação brasileira de turismo. Lei n. 8.181, de 28 de março de 1991. Disponível em: <http:/ / aulasturismo. blogspot.com/2008/03/lei-n-8181-de-28-de-marçode-1991.html>. Acesso em: 6 set. 2011.

LINCH, K. A imagem da cidade. São Paulo: Martins Fontes, 1997.
MORENO, J. O futuro das cidades. São Paulo: SENAC, 2002. PEIXOTO, N. B. Paisagens urbanas. 3. ed. São Paulo: SENAC, 2004.

POZO Y BARAJAS, A. Del. La condicion post moderna: ideas de ciudad. Sevilla: Universidade de Sevillla, 2009.

ROSSI, A. A arquitetura da cidade. 2. ed. São Paulo: Martins Fontes, 1995.

SANTOS, R. I. C.; GOULART, M. Uma abordagem histórico-cultural do turismo. Turismo: visão e ação, Itajaí, v. 1, n. 1, p. 19-29, jan./jun. 1998.

VARGAS, H. C.; CASTILHO, A. L. H. Intervenções em centros urbanos. 2. ed. rev. e atual. Barueri: Manole, 2009.

VAZ, L. F.. Planos e projetos de regeneração cultural: notas sobre uma tendência urbanística recente. In: SEMINÁRIO DA HISTÓRIA DA CIDADE E DO URBANISMO, 8., 2004, Niterói. Anais... Rio de Janeiro: PROURB/FAU/UFRJ, 2004. CD-ROM. 